\title{
The Metabolism of Low Density Lipoprotein in Familial Type II Hyperlipoproteinemia
}

\author{
Terry Langer, Warren Strober, and Robert I. LeVy \\ From the Molecular Disease Branch, National Heart and Lung Institute and \\ Metabolism Branch, National Cancer Institute, National Institutes of Health \\ Bethesda, Maryland 20014
}

A B S T R A C T The metabolism of low density lipoprotein (LDL, beta lipoprotein) was studied in 10 normal individuals and 10 patients with familial type II hyperlipoproteinemia using purified radioiodinated LDL. Over $97 \%$ of the label was bound to the protein moiety of LDL and therefore the turnover data reflect the fate and distribution of LDL-apoprotein. Comparison of the metabolic behavior of biologically screened and unscreened labeled LDL preparations in dogs as well as the analysis of the urinary excretion of radioiodide derived from labeled LDL degradation in humans indicated that no significant denaturation resulted from the isolation, purification, and labeling techniques.

The plasma concentration of LDL-cholesterol in normals was $105 \pm 21 \mathrm{mg} / 100 \mathrm{ml}$ (mean $\pm 1 \mathrm{sD}$ ) in contrast to $254 \pm 47 \mathrm{mg} / 100 \mathrm{mg}$ in patients with type II hyperlipoproteinemia; these values corresponded to LDL-apoprotein concentrations of $63 \pm 13 \mathrm{mg} / 100 \mathrm{ml}$ and $153 \pm 30$ $\mathrm{mg} / 100 \mathrm{ml}$, respectively. Despite these differences in concentration, the synthetic rate of LDL-apoprotein in both groups was not significantly different (14.43 \pm 1.75 $\mathrm{mg} / \mathrm{kg}$ per day in normals vs. $15.01 \pm 1.71 \mathrm{mg} / \mathrm{kg}$ per day in type II) nor was there any difference in the fraction of the total exchangeable LDL which was in the intravascular space $(68.4 \pm 4.3 \%$ vs. $73.3 \pm 5.2 \%)$. However, the fractional catabolic rate of LDL in normal individuals differed significantly from that of patients with type II hyperlipoproteinemia $(0.462 \pm 0.077 /$ day in normals vs. $0.237 \pm 0.044 /$ day in type II) and correspondingly the biological half-life of LDL was significantly

This work was presented in part at the 61st Annual Meeting of the American Society for Clinical Investigation, Atlantic City, N. J., May 1969 and published in abstract form (1).

Dr. Langer's present address is Department of Medicine, The Hospital of the University of Pennsylvania, Philadelphia, Pa. 19104.

Received for publication 22 November 1971 and in revised form 10 Jamuary 1972. prolonged ( $3.08 \pm 0.35$ days normals vs. $4.68 \pm 0.44$ days in type II).

These data indicate that the pathologic elevation of plasma LDL concentration in the individuals with type II hyperlipoproteinemia studied here is due to a decreased fractional rate of LDL degradation rather than to an abnormality of LDL synthesis. This defect of catabolism may be the primary defect in type II hyperlipoproteinemia or, alternatively, may be secondary to an underlying abnormality in lipid metabolism.

\section{INTRODUCTION}

Familial type II hyperlipoproteinemia is a lipid transport disorder transmitted as an autosomal dominant and characterized by a marked elevation in the concentration of plasma low density ( $S_{\mathrm{f}} 0-12$, density $1.019-1.063$ ) beta lipoprotein (LDL), ${ }^{1}$ hypercholesterolemia, xanthomatosis, and premature coronary atherosclerosis (2).

The primary metabolic abnormalities responsible for the hyperlipoproteinemia and hypercholesterolemia in type II patients have not been elucidated. One possibility is that the abnormality in type II hyperlipoproteinemia involves a defect in the metabolism of LDL and more specifically that of the protein moiety of LDL rather than one of its lipid constituents (3). To study this question we have performed, and now report on, metabolic studies with purified, radioiodinated plasma LDL in normal individuals and patients with type II hyperlipoproteinemia.

\section{METHODS}

\section{Patients}

Normal patients. 10 normal patients (6 men and 4 women) were studied. Clinical data for these individuals

${ }^{1}$ Abbreviations used in this paper: FCR, fractional catabolic rate; LDL, low density lipoprotein; P, plasma; U, urinary. 
are summarized in Table I. Each patient had normal thyroid, hepatic, and renal function and normal glucose tolerance tests. None of the normal patients had a family history of hyperlipoproteinemia.

Type II patients. 10 patients with heterozygous familial type II hyperlipoproteinemia were studied $(6$ men and 4 women). Clinical data for these patients are summarized in Table II. The clinical diagnosis was established in all 10 by: (a) the presence of marked elevations of plasma LDL in the absence of clinical or chemical evidence of other disorders associated with secondary hyperbetalipoproteinemia (i.e., hypothyroidism, hepatic disease, nephrotic syndrome, or dysglobulinemia) (3), (b) the presence of at least one similarly affected first degree relative, and $(c)$ the presence of characteristic tendon xanthomata.

All patients were studied on the metabolic wards of the Clinical Center of the National Heart and Lung Institute and were fed a balanced diet containing $<300 \mathrm{mg}$ of cholesterol/day and a ratio of polyunsaturated to saturated fat of approximately $2.5 / 1$ with $40 \%$ of the calories derived from fat, $40 \%$ from carbohydrate, and $20 \%$ from protein. Body weight, total plasma cholesterol, triglyceride, and LDLcholesterol concentrations were measured serially throughout each study period and remained constant. None of the patients or volunteers were taking medications during the period of study.

\section{Preparation of LDL}

LDL was prepared from plasma of type II patients and normals. Blood $(150 \mathrm{ml})$ was collected in sterile, pyrogenfree plastic bags containing a $1 \%$ solution of the disodium salt of ethylenediaminetetraacetic acid (EDTA) (15 ml). The plasma was immediately separated by centrifugation at $4^{\circ} \mathrm{C}$ and its density adjusted to $1.019 \mathrm{~g} / \mathrm{ml}$ by the addition of a solution of $\mathrm{NaCl}-\mathrm{KBr}$ of density $1.085 \mathrm{~g} / \mathrm{ml}$. The plasma was then subjected to preparative ultracentrifugation for $12 \mathrm{hr}$ at $40,000 \mathrm{rpm}$ in a Spinco No. 40 rotor (Beckman Instruments, Inc., Fullerton, Calif.) after which the $\mathrm{d}<1.019 \mathrm{~g} / \mathrm{ml}$ (i.e., $\mathrm{S}_{\mathrm{f}}>12$ ) supernate was removed by tube slicing. The infranate was then adjusted to a density of $1.063 \mathrm{~g} / \mathrm{ml}$ by the addition of $\mathrm{NaCl}-\mathrm{KBr}$ solution of density $1.35 \mathrm{~g} / \mathrm{ml}$ and subjected to further ultracentrifuga-

TABLE I

Clinical Data, Normals*

\begin{tabular}{|c|c|c|c|c|c|c|}
\hline Initials & Sex & Age & Weight & $\begin{array}{l}\text { Plasma } \\
\text { choles- } \\
\text { terol }\end{array}$ & $\begin{array}{c}\text { LDL } \\
\text { choles- } \\
\text { terol }\end{array}$ & $\begin{array}{l}\text { Plasma } \\
\text { glycer- } \\
\text { ides }\end{array}$ \\
\hline & & $y r$ & kg & $\begin{array}{c}\mathrm{mg} / \\
100 \mathrm{ml}\end{array}$ & $\begin{array}{c}\mathrm{mg} / \\
100 \mathrm{ml}\end{array}$ & $\begin{array}{c}\mathrm{mg} / \\
100 \mathrm{ml}\end{array}$ \\
\hline A. $\mathrm{R}$. & $\mathrm{F}$ & 42 & 60.1 & 167 & 116 & 72 \\
\hline J. R. & F & 24 & 47.0 & 189 & 151 & 134 \\
\hline N. E. & F & 21 & 52.9 & 134 & 84 & 62 \\
\hline B. S. & $F$ & 21 & 67.8 & 172 & 114 & 52 \\
\hline S. G. & $\mathbf{M}$ & 24 & 75.2 & 114 & 82 & 66 \\
\hline A. A. & $\mathbf{M}$ & 21 & 57.5 & 153 & 119 & 81 \\
\hline B. S. & $\mathbf{M}$ & 22 & 64.6 & 147 & 108 & 89 \\
\hline E. S. & $\mathbf{M}$ & 26 & 60.0 & 142 & 100 & 51 \\
\hline B. V. C. & $\mathbf{M}$ & 22 & 70.6 & 142 & 89 & 47 \\
\hline B. B. & $\mathbf{M}$ & 22 & 72.7 & 153 & 88 & 81 \\
\hline
\end{tabular}

* Lipid values are those obtained after 2 wk on a low cholesterol, high polyunsaturated/saturated ratio diet (see text).
TABLE II

Clinical Data, Type II Patients*

\begin{tabular}{lcccccc}
\hline Initials & Sex & Age & Weight & $\begin{array}{c}\text { Plasma } \\
\text { choles- } \\
\text { terol }\end{array}$ & $\begin{array}{c}\text { LDL } \\
\text { choles- } \\
\text { terol }\end{array}$ & $\begin{array}{c}\text { Plasma } \\
\text { glycer- } \\
\text { ides }\end{array}$ \\
\hline & & $y r$ & $k g$ & $m g /$ & $\mathrm{mg} /$ & $\mathrm{mg} /$ \\
B. C. & F & 34 & 54.6 & 359 & 308 & 136 \\
M. B. & F & 62 & 61.1 & 324 & 249 & 135 \\
T. G. & F & 27 & 62.5 & 238 & 196 & 73 \\
A. B. & F & 39 & 48.5 & 355 & 271 & 106 \\
H. J. & M & 36 & 72.4 & 373 & 310 & 134 \\
J. B. & M & 32 & 57.6 & 254 & 190 & 85 \\
G. H. & M & 35 & 83.7 & 365 & 273 & 204 \\
H. K. & M & 49 & 55.5 & 341 & 304 & 162 \\
A. L. & M & 48 & 70.2 & 287 & 236 & 139 \\
S. T. & M & 40 & 75.7 & 300 & 204 & 96 \\
\hline
\end{tabular}

* Lipid values are those obtained after $2 \mathrm{wk}$ on a low cholesterol, high polyunsaturated/saturated ratio diet (see text).

tion for $12 \mathrm{hr}$ in a Spinco No. 65 rotor at $65,000 \mathrm{rpm}$ after which the supernate containing lipoprotein of density range $1.019-1.063 \mathrm{~g} / \mathrm{ml}$ was isolated. This material was then washed and concentrated by a final ultracentrifugation after carefully overlayering with $\mathrm{NaCl}-\mathrm{KBr}$ solution of density $1.063 \mathrm{~g} / \mathrm{ml}$. As a final purification step, concentrated LDL was dialyzed overnight against $0.15 \mathrm{M} \mathrm{NaCl}$ containing $0.1 \%$ EDTA, $\mathrm{pH} 7.4$, in order to remove $\mathrm{KBr}$ and return the preparation to plasma density $(1.006 \mathrm{~g} / \mathrm{ml})$.

Each preparation of LDL used in turnover studies was demonstrated to be free of contaminating lipoproteins by immunoelectrophoresis in agarose gel employing specific antisera prepared against high density (alpha), low density (beta) lipoproteins, and very low density lipoprotein apoproteins (4). In addition, no other contaminating serum proteins were found using antisera reacting with albumin, gamma globulin, and whole human serum (4).

Canine LDL was prepared in a similar fashion, except that the lipoprotein of $\mathrm{d}=1.019-1.050$ was isolated to minimize contamination with $\mathrm{HDL}$ which, in the dog, is present in considerably greater amounts than LDL. In addition, tests of lipoprotein purity were conducted using antisera specific for canine plasma proteins and lipoproteins.

\section{Radioiodination}

Radiolabeling of LDL was carried out using a modification of the iodine monochloride method of McFarlane (5). Purified LDL protein (10-40 mg) in a volume of $1.0-1.5$ $\mathrm{ml}$ was labeled with carrier-free ${ }^{125} \mathrm{I}$ at $4^{\circ} \mathrm{C}$ in $1.0 \mathrm{M}$ glycine- $\mathrm{NaOH}$ buffer, $\mathrm{pH} 10$. In vitro studies revealed that the efficiency of iodination, i.e. the fraction of the radioiodine in the reaction mixture which is bound to LDL, was maximal at $\mathrm{pH} 9.0-10.0$, but the proportion of the label which was bound to lipid (rather than protein) was minimal at the higher $\mathrm{pH}$ (Fig. 1). The efficiency of iodination at $\mathrm{pH} 10$ was $10-25 \%$ and this resulted in the attachment of approximately 0.5 atoms of iodine to each LDL molecule (assuming a molecular weight for LDL of $2 \times 10^{\circ}(6,7)$ of which $25 \%$ by weight is protein [8]).

Unbound iodine was removed by dialysis vs. $0.15 \mathrm{M} \mathrm{NaCl}$, $0.1 \%$ EDTA, $\mathrm{pH}$ 7.4. After dialysis the ${ }^{125} \mathrm{I}-\mathrm{LDL}$ preparations all contained less than $1 \%$ free ${ }^{125} \mathrm{I}$ as determined by 


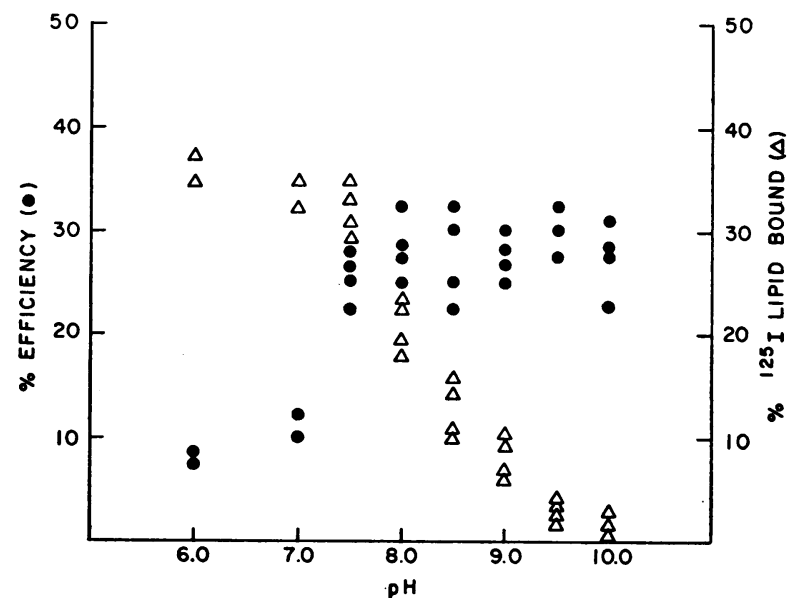

FIGURE 1 Effect of $\mathrm{pH}$ of iodination medium on efficiency of iodination ( $\bullet$ ) and percentage of ${ }^{125} \mathrm{I}$ bound to the lipid moiety of LDL $(\triangle)$.

precipitation with $10 \%$ trichloroacetic acid (TCA) and $5 \%$ phosphotungstic acid in the presence of carrier albumin, cold LDL, or plasma.

The extent of lipid labeling was determined by extraction of labeled LDL with a 2:1 chloroform: methanol solvent (9). It was found that the fraction of radioiodine bound to lipid was related to the overall efficiency of the labeling procedure and to the $\mathrm{pH}$. Lipid labeling was minimal at higher $\mathrm{pH}$ : the mean fraction of lipid extractable lipoproteinbound radioiodine was $2.4 \%$ (range $1.8-3.4 \%$ ) at $\mathrm{pH} 10$. The distribution of lipid-bound radioactivity among the various lipid constituents of LDL was determined by thinlayer chromatography of chloroform-methanol extracts. The lipid extracts were evaporated to dryness under nitrogen, redissolved with small amounts of $\mathrm{CHCl}_{3}-\mathrm{CH}_{3} \mathrm{OH}$ solvent, applied to thin-layer chromatographic plates, and run in polar (chloroform-ethanol-water: : 195: 75:12) and nonpolar (petroleum ether : ethyl ether: glacial acetic acid: : $90: 10: 1$ ) solvent systems along with appropriate standards (10). The plates were dried, stained with anisaldehyde or iodine vapor, and the bands sequentially scraped and counted. The major portion of lipid-bound ${ }^{125} \mathrm{I}$ was associated with phospholipids, especially lecithin, with smaller amounts associated with free cholesterol, cholesterol ester, and glyceride.

The iodination procedure did not affect the electrophoretic behavior or immunologic reactivity of the LDL as demonstrated by simultaneous agarose-gel immunoelectrophoresis (4) and paper electrophoresis (11) of unlabeled and radiolabeled LDL. Furthermore, the paper electrophoretograms were scanned to localize small amounts of labeled proteins which did not migrate with LDL; in all cases, $>95 \%$ of the radioactivity was localized to the beta $_{2}$ globulin band characteristic of native $\mathrm{LDL}$

Iodination did not affect the flotation characteristics of LDL. The ${ }^{125} \mathrm{I}-\mathrm{LDL}$ was mixed with human plasma from a normal fasting individual and ultracentrifuged at densities 1.006, 1.019, 1.063, and $1.21 \mathrm{~g} / \mathrm{ml}$ (after addition of appropriate quantities of $\mathrm{NaCl}-\mathrm{KBr}$ solution and solid $\mathrm{KBr}$ ) to determine if gross alterations in flotation were produced by radioiodination. These studies demonstrated that $>98 \%$ of the radioactivity could be recovered between densities 1.019 and $1.063 \mathrm{~g} / \mathrm{ml}$.

\section{Preparation of ${ }^{125} \mathrm{I}-\mathrm{LDL}$ for in vivo studies}

Immediately after removal of unbound ${ }^{125} \mathrm{I}$ by dialysis, sterile human albumin was added to the ${ }^{125} \mathrm{I}-\mathrm{LDL}$ preparations to minimize damage due to self-radiation. The preparation was then passed through a $0.45 \mathrm{~m} \mu$ Millipore filter (Millipore Corp., Bedford, Mass.) and tested for sterility and pyrogenicity before in vivo studies. Final dilutions of each preparation were made with buffered saline containing $0.1 \%$ EDTA; such dilutions contained $35 \mathrm{mg} / \mathrm{ml}$ of albumin and $10 \mu \mathrm{Ci} / \mathrm{ml}$ of ${ }^{125} \mathrm{I}-\mathrm{LDL}$. The ${ }^{125} \mathrm{I}-\mathrm{LDL}$ was usually considered ready for reinjection approximately $96 \mathrm{hr}$ after the original plasma sample was obtained.

\section{Study protocol}

Metabolic studies in dogs. Mongrel dogs weighing approximately $20 \mathrm{~kg}$ were placed in metabolic cages with free access to food and water containing sodium iodide. To obtain ${ }^{125} \mathrm{I}$-LDL plasma decay curves, $25-50 \mu \mathrm{Ci}$ of ${ }^{125} \mathrm{I}-\mathrm{LDL}$ prepared as described above were administered intravenously to fasting animals and serial blood samples obtained from the opposite foreleg $10 \mathrm{~min}$ after injection and daily for 7-10 days thereafter. A series of "screening" experiments were conducted to detect the presence of denatured, rapidly degradable protein in the ${ }^{125} \mathrm{I}-\mathrm{LDL}$ preparations. In these experiments a first set of dogs was injected with $1-2 \mathrm{mCi}$ of freshly prepared ${ }^{125} \mathrm{I}-\mathrm{LDL}$ and then plasmapheresed approximately $24 \mathrm{hr}$ later. During this period these animals clear and degrade any denatured material which is present in the preparation. The residual "biologically screened" ${ }^{125} \mathrm{I}-$ LDL contained in the $24 \mathrm{hr}$ plasma sample is then reinjected into a second set of dogs and plasma samples collected as in the usual study.

Metabolic studies in humans. Fasting, supine patients and normals were administered $25-50 \mu \mathrm{Ci}$ of ${ }^{125} \mathrm{I}-\mathrm{LDL}$ (approximately $1-2 \mathrm{mg}$ of LDL apoprotein) intravenously from a calibrated syringe via a continuous saline infusion. Subsequently, $10-\mathrm{ml}$ blood samples were collected in glass tubes containing EDTA at 10 min ("zero time"), 1, 4, 8, 12, 24, $36,48,60$, and $72 \mathrm{hr}$ and then daily for 14 days. The plasma was immediately separated at $4^{\circ} \mathrm{C}$ and portions removed for counting and total cholesterol determinations. 40-ml fasting samples were obtained on days $1,3,7,10$, and 14 and subjected to complete lipoprotein quantification (3). $24 \mathrm{hr}$ urine specimens were collected in glass jars containing small amounts of $\mathrm{KI}, \mathrm{NaHSO}_{3}$, and $\mathrm{NaOH}$ to minimize volatilization of ${ }^{125} \mathrm{I}$ or its adsorption to glass. The patients received $1.0 \mathrm{~g}$ of $\mathrm{KI}$ daily by mouth in divided doses for 3 days before and throughout each study to inhibit uptake of radioiodine by the thyroid. Informed consent was obtained from each patient and normal volunteer.

\section{Sample analysis}

2-ml portions of the daily plasma samples and $5-\mathrm{ml}$ portions from the 24-hr urine collections were counted along with appropriate standards in an automatic gamma-ray, well-type scintillation counter. In early studies, every plasma sample was precipitated with $10 \%$ TCA to determine if nonprotein-bound ${ }^{125} \mathrm{I}$ accounted for a significant proportion of radioactivity. In every case it was found that $<3 \%$ of the radioactivity consisted of nonprotein-bound iodide; hence in later studies this procedure was discontinued and it was assumed that total plasma radioactivity represented proteinbound ${ }^{125} \mathrm{I}$.

Each plasma sample was analyzed for total cholesterol content. In addition, larger samples were obtained during 
each study for a more complete lipid analysis including determination of triglycerides, high density, low density, and very low density lipoprotein cholesterol concentration using methods previously described (3). In these studies, LDL of density $1.019-1.063 \mathrm{~g} / \mathrm{ml}$ was isolated separately for lipid analysis. Portions of the larger samples were also subjected to ultracentrifugation at densities $1.006,1.019,1.063$, and $1.21 \mathrm{~g} / \mathrm{ml}$ to determine the flotation characteristics of the circulating ${ }^{125} \mathrm{I}-\mathrm{LDL}$. Finally, a portion of the original purified, unlabeled LDL isolated from each subject was also analyzed for protein (12), total cholesterol (13), triglyceride (14), and phospholipid (15).

\section{Data analysis}

The metabolic parameters governing the turnover of LDL were calculated by methods described by Matthews (16) and by Nosslin (17) for the analysis of plasma decay curves (Fig. 2, upper panel).

The fractional catabolic rate (FCR) (the fraction of the intravascular LDL pool catabolized per day) was calculated using the expression: Fractional catabolic rate $=1 /\left(\mathrm{C}_{1} / \mathrm{b}_{1}\right.$ $\left.+C_{2} / b_{2}\right)$, where $C_{n}$ and $b_{n}$ are the $y$ intercepts and slopes of the plasma radioactivity decay curve and its peeled expo-

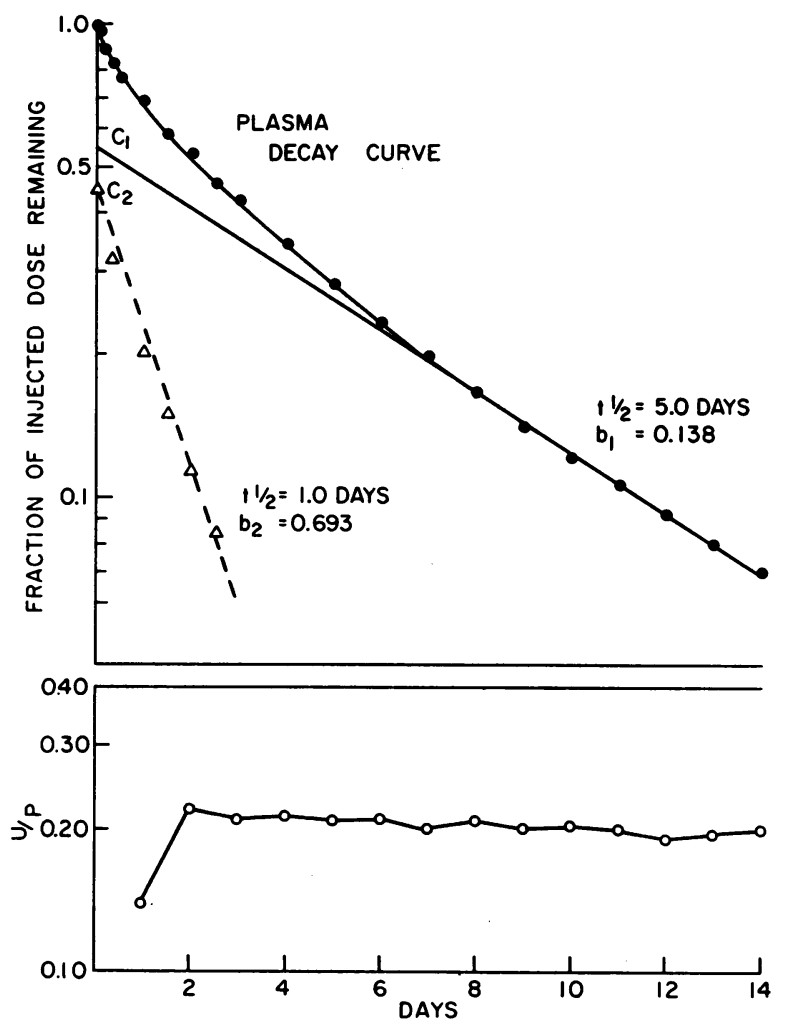

FIgure 2 Upper panel: Typical LDL plasma decay curve with exponentials. First exponential is the terminal (linear) portion of decay curve extrapolated to zero time. Second exponential is the plot of values obtained from subtracting first exponential from original decay curve. Lower panel: Metabolic clearance values (U/P values) of $L D L$ plotted for each day of a typical study. Initial value is low because of delay in iodide excretion. Constancy of subsequent values indicates metabolic homogeneity of labeled LDL. nentials (see reference 16). The distribution of LDL between the intravascular and extravascular compartments was calculated using the expression:

$$
\% \text { intravascular }=\left[\frac{\mathrm{C}_{1}}{\mathrm{~b}_{1}}+\frac{\mathrm{C}_{2}}{\mathrm{~b}_{2}}\right]^{2} / \frac{\mathrm{C}_{1}}{\left(\mathrm{~b}_{1}\right)^{2}}+\frac{\mathrm{C}_{2}}{\left(\mathrm{~b}_{2}\right)^{2}} .
$$

The plasma volume was calculated by isotopic dilution using the $10 \mathrm{~min}$ plasma sample on the assumption that during this interval the distribution of ${ }^{125} \mathrm{I}-\mathrm{LDL}$ was uniform and that insignificant amounts of labeled lipoprotein were catabolized or entered the extravascular compartment. The total intravascular LDL-cholesterol pool was computed from the product of the LDL-cholesterol concentration (the mean of five determinations of LDL-cholesterol concentration during each study) and the plasma volume. The intravascular LDL-apoprotein pool was then calculated from the product of the LDL-cholesterol pool and the ratio of LDLapoprotein/LDL-cholesterol which was measured for each subject. (This ratio was approximately 0.6 ).

The steady-state synthetic rate (or absolute catabolic rate) was then calculated as follows: synthetic rate $=F C R \times$ intravascular LDL-apoprotein. The synthetic rate was expressed as milligrams of apoprotein synthesized per day normalized for body weight (milligrams/kilogram per day).

In addition to the method described above for the calculation of the fractional catabolic rate (which relies solely on the plasma decay curve) an independent estimate of the FCR was obtained from the daily urinary radioactivity excretion using the metabolic clearance method of Berson and Yalow (18). With this method, the clearance of ${ }^{125} \mathrm{I}-\mathrm{LDL}$ is calculated for each day of the study from the ratio of total urinary radioactivity excreted in each $24 \mathrm{hr}$ period to the mean plasma radioactivity during that interval (Fig. 2, lower plane). This $U / P$ ratio is an accurate estimate of the fractional catabolic rate provided the rate of iodide excretion is rapid compared to rate of LDL breakdown.

\section{RESULTS}

\section{Animal studies}

The mean fractional catabolic rate $( \pm 1 \mathrm{SD})$ of unscreened human ${ }^{120} \mathrm{I}$-LDL obtained in eight dogs using four different protein preparations was $0.0338 \pm 0.0030$ of the intravascular pool/hr $(0.810 \pm 0.070 /$ day $)$; this corresponded to a biological half-life of $26.6 \pm 1.7 \mathrm{hr}$. The FCR and biological half-life of four additional preparations of human ${ }^{125} \mathrm{I}-\mathrm{LDL}$ which had first been screened for $18-24 \mathrm{hr}$ in dogs was $0.0326 \pm 0.0019 / \mathrm{hr} \quad(0.781 \pm$ $0.045 /$ day) corresponding to a biological half-life of $27.0 \pm 0.8$ days; these values were not significantly different from the unscreened preparations $(P>0.4)$ and there was therefore no evidence for the presence of rapidly degradable protein in the ${ }^{125} \mathrm{I}-\mathrm{LDL}$ preparations. It was of interest that ${ }^{125} \mathrm{I}-\mathrm{LDL}$ injected into a dog $2 \mathrm{wk}$ after labeling contained a considerable amount of rapidly degradable material; in this case the plasma decay curve showed a rapid early decline followed by a normal terminal slope. This observation suggests that radioactive LDL must be used promptly after purification and labeling. 
TABLE III

Metabolic Parameters, Normals

\begin{tabular}{|c|c|c|c|c|c|c|c|c|}
\hline \multirow[t]{2}{*}{ Initials } & \multirow{2}{*}{$\begin{array}{c}\begin{array}{c}\text { Plasma } \\
\text { volume }\end{array} \\
m l\end{array}$} & \multirow{2}{*}{$\begin{array}{c}\begin{array}{c}\text { Plasma } \\
\text { APO-LDL }\end{array} \\
m g / \\
100 \mathrm{ml}\end{array}$} & \multirow{2}{*}{$\begin{array}{c}\begin{array}{c}\text { Intra- } \\
\text { vascular* }\end{array} \\
\%\end{array}$} & \multicolumn{2}{|c|}{$\begin{array}{l}\text { Fractional cata- } \\
\text { bolic rate }\end{array}$} & \multirow{2}{*}{$\frac{\begin{array}{c}\text { Biological } \\
\text { half-life }\left(t^{\frac{1}{3}}\right)\end{array}}{\text { days }}$} & \multicolumn{2}{|c|}{ Synthetic rate } \\
\hline & & & & $\begin{array}{c}\text { fraction of } \\
\text { At }\end{array}$ & $\begin{array}{c}\text { pool/day } \\
\text { B } 8\end{array}$ & & $m g / d a y$ & $\begin{array}{c}m g / k g \\
\text { per day }\end{array}$ \\
\hline A. $\mathrm{R}$. & 2927 & 70 & 65.2 & 0.452 & 0.365 & 3.58 & 926 & 15.4 \\
\hline J. R. & 2250 & 91 & 66.4 & 0.418 & 0.400 & 3.33 & 856 & 18.2 \\
\hline N. E. & 2807 & 51 & 64.4 & 0.528 & 0.486 & 3.00 & 756 & 14.3 \\
\hline B. S. & 2616 & 80 & 69.2 & 0.398 & 0.385 & 3.00 & 1041 & 15.3 \\
\hline S. G. & 3515 & 49 & 75.0 & 0.633 & 0.653 & 2.25 & 1090 & 14.5 \\
\hline A. A. & 2737 & 72 & 69.8 & 0.385 & 0.364 & 3.25 & 759 & 13.2 \\
\hline B. S. & 3102 & 65 & 66.4 & 0.445 & 0.370 & 3.25 & 897 & 13.9 \\
\hline E. S. & 2780 & 60 & 70.0 & 0.455 & 0.423 & 3.00 & 759 & 12.5 \\
\hline B. V. C. & 3410 & 62 & 75.3 & 0.393 & 0.405 & 3.10 & 841 & 12.0 \\
\hline B. B. & 3432 & 62 & 62.6 & 0.511 & 0.492 & 3.17 & 1087 & 15.0 \\
\hline
\end{tabular}

* Per cent of APO-LDL pool in intravascular compartment.

¥ Calculated from serum decay curve by method of Matthews'(16); see text.

$\S$ Calculated from $U / P$ ratios; see text.

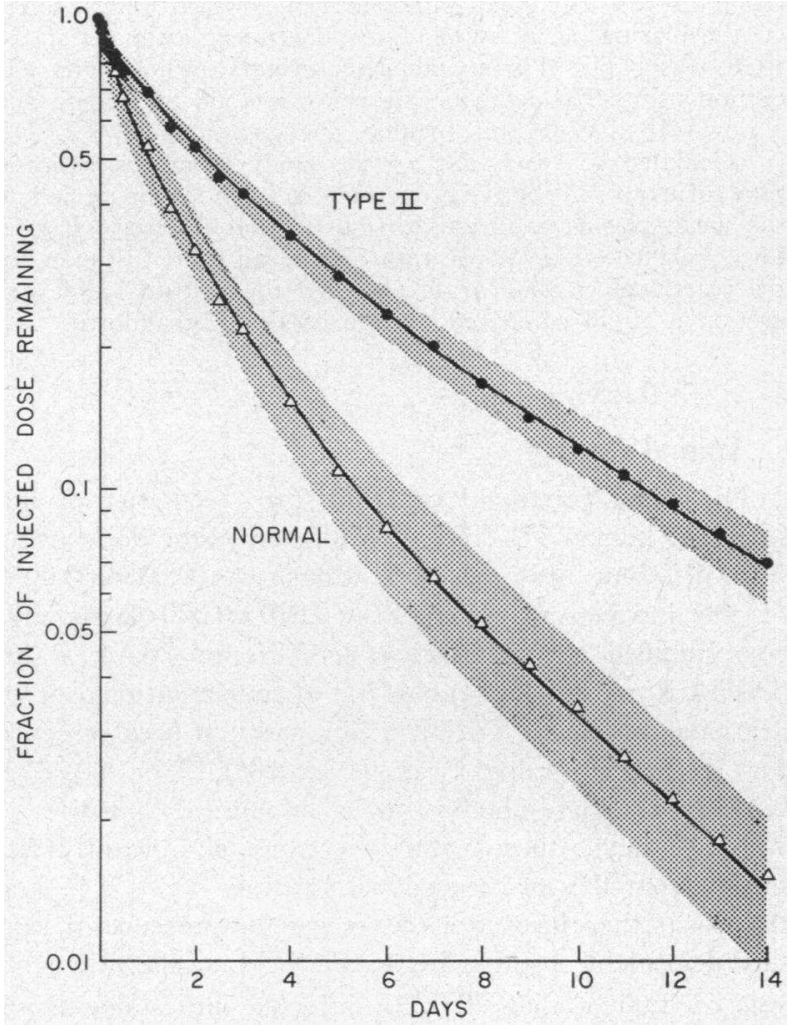

Figure 3 Mean plasma decay (die-away) curves for normal individuals $(\Delta)$ and patients with type II hyperlipoproteinemia (๑). Shaded areas indicate 1 SD on either side of mean. Since the fractional catabolic rate is equal to the reciprocal of the areas under these curves, it is clear that type II patients have a lower fractional catabolic rate than normal individuals.
Identical plasma decay curves were observed when ${ }^{125}$ I-LDL obtained from normal individuals and patients with type II hyperlipoproteinemia were injected into dogs, suggesting that there are no major structural differences in the LDL molecules from these two sources. On the other hand, canine LDL demonstrated a considerably slower rate of degradation than LDL from human sources. In this case the FCR was 0.0262 of the intravascular pool/hr (0.628/day) and the biological half-life was $38.5 \mathrm{hr}$.

Throughout each study in the dogs, greater than $95 \%$ of the plasma radioactivity could be reisolated between the densities 1.019 and $1.063 \mathrm{~g} / \mathrm{ml}$ and less than $1 \%$ of the radioactivity was found in the density $1.21 \mathrm{~g} / \mathrm{ml}$ infranate, indicating that, in the dog, the labeled LDL circulates as an intact lipoprotein and does not associate with or become converted to lipoproteins of other densities.

\section{Human studies}

LDL metabolism in normal subjects (Table III) (Figs. 3 and 4). In 10 normal individuals the mean FCR of autologous LDL was $0.462 \pm 0.077$ of the intravascular pool/day (range $0.385-0.633 /$ day) and the mean biological half-life was $3.08 \pm 0.35$ days (range $2.25-3.58$ days). The mean synthetic rate of LDL apoprotein was $14.43 \pm 1.75 \mathrm{mg} / \mathrm{kg}$ per day (range $12.0-18.2 \mathrm{mg} / \mathrm{kg}$ per day) or $901.2 \pm 132.2 \mathrm{mg} /$ day (range: $756-1090 \mathrm{mg}$ / day).The mean percentage of the total exchangeable LDL confined to the intravascular compartment was $68.4 \pm 4.3 \%$ (range $62.6-75.0 \%$ ).

LDL metabolism in subjects with familial type II hyperlipoproteinemia (Table IV) (Figs. 3 and 4). In 10 
patients with type II hyperlipoproteinemia the mean FCR of autologous LDL was $0.237 \pm 0.044$ of the intravascular pool/day (range: $0.205-0.352$ of the intravascular pool/day) and the mean biological half-life was $4.68 \pm 0.044$ days (range : $3.80-5.17$ days) ; both of these parameters are significantly different from normal $(P<$ $0.001)$. The mean synthetic rate of LDL-apoprotein was $15.01 \pm 1.71 \mathrm{mg} / \mathrm{kg}$ per day (range: $12.2-17.5 \mathrm{mg} / \mathrm{kg}$ per day) or $955.0 \pm 147.5 \mathrm{mg} /$ day (range: $769-1255 \mathrm{mg}$ / day) and $73.3 \pm 5.2 \%(65.0-83.2 \%)$ of the total exchangeable LDL was in the intravascular space. The synthetic rate of LDL in type II patients was not significantly different from normal $(P>0.4)$, nor was the distribution of LDL among the body spaces $(P>0.05)$.

$U / P$ ratios. In all studies the fractional catabolic rate obtained from the mean $U / P$ ratio was in close agreement with the FCR calculated from the plasma decay curve (Tables III and IV). The $U / P$ ratio for the 1st day of each turnover study was always considerably lower than for succeeding days and this value was excluded from the calculations. This finding was attributed to the normal delay in iodide excretion after ${ }^{125} \mathrm{I}$ LDL catabolism. The $U / P$ ratio for the remainder of each study was constant except for a few cases within the normal group when this parameter decreased slightly in the last few days of the study at a time when the total remaining plasma radioactivity was considerably less than $3 \%$ of the injected dose. This gradual decline in the $U / P$ ratio was not seen in any study involving patients with type II hyperlipoproteinemia including one study which was continued for an additional 7 days. It was concluded from the constancy of the $U / P$ ratio that the ${ }^{125} \mathrm{I}-\mathrm{LDL}$ molecules in each preparation had

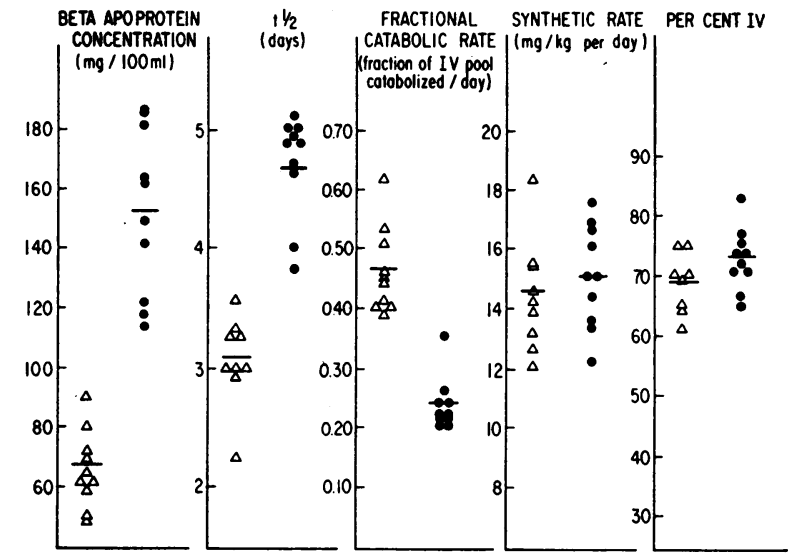

FIgURE 4 Parameters of LDL metabolism in normal individuals $(\Delta)$ and patients with type II hyperlipoproteinemia (๑). Fractional catabolic rate of LDL is greatly reduced in the patient group (3rd panel) whereas synthetic rate is normal (4th panel). Horizontal bars represent mean values.

uniform metabolic behavior and that no significant amounts of rapidly degradable protein were present.

Flotation of plasma ${ }^{125} I-L D L$. Throughout each study, greater than $95 \%$ of the circulating radioactivity was recovered by ultracentrifugation between densities 1.019 and $1.063 \mathrm{~g} / \mathrm{ml}$, with less than $1 \%$ in the $1.21 \mathrm{~g} / \mathrm{ml}$ infranate. These data confirmed the in vitro and animal studies and provided evidence that LDL-apoprotein is not converted or incorporation into lipoproteins of other density classes, nor does it circulate in significant amounts as the free apoprotein at a density greater than $1.21 \mathrm{~g} / \mathrm{ml}$.

The metabolism of isologous ${ }^{125} I-L D L$ in patients with type II hyperlipoproteinemia. To determine if

TABLE IV

Metabolic Parameters, Type II Patients

\begin{tabular}{|c|c|c|c|c|c|c|c|c|}
\hline \multirow[t]{3}{*}{ Initials } & \multirow{3}{*}{$\begin{array}{c}\begin{array}{c}\text { Plasma } \\
\text { volume }\end{array} \\
m l\end{array}$} & \multirow{3}{*}{$\begin{array}{c}\begin{array}{c}\text { Plasma } \\
\text { APO-LDL }\end{array} \\
\mathrm{mg} / \\
100 \mathrm{ml}\end{array}$} & \multirow{3}{*}{$\begin{array}{c}\begin{array}{c}\text { Intra- } \\
\text { vascular* }\end{array} \\
\%\end{array}$} & \multicolumn{2}{|c|}{$\begin{array}{c}\text { Fractional cata- } \\
\text { bolic rate }\end{array}$} & \multirow{3}{*}{$\begin{array}{c}\begin{array}{c}\text { Biological } \\
\text { half-life }\left(\mathrm{t} \frac{1}{2}\right)\end{array} \\
\text { days }\end{array}$} & \multicolumn{2}{|c|}{ Synthetic rate } \\
\hline & & & & fraction 0 & pool/day & & $m g / d a y$ & $m g / k g$ \\
\hline & & & & Af & B§ & & & per day \\
\hline B. C. & 2234 & 185 & 71.6 & 0.211 & 0.207 & 5.17 & 872 & 16.0 \\
\hline M. B. & 2500 & 149 & 74.1 & 0.221 & 0.221 & 4.90 & 823 & 13.5 \\
\hline T. G. & 2694 & 118 & 65.0 & 0.352 & 0.348 & 3.80 & 1038 & 16.6 \\
\hline A. B. & 1940 & 163 & 74.2 & 0.257 & 0.241 & 4.00 & 812 & 16.7 \\
\hline H. J. & 2681 & 186 & 72.3 & 0.217 & 0.215 & 5.00 & 1082 & 15.0 \\
\hline J. B. & 2835 & 114 & 71.9 & 0.238 & 0.238 & 4.70 & 769 & 13.3 \\
\hline G. H. & 3430 & 164 & 83.2 & 0.223 & 0.236 & 4.67 & 1255 & 15.0 \\
\hline H. K. & 2601 & 182 & 76.5 & 0.205 & 0.208 & 4.93 & 970 & 17.5 \\
\hline S. T. & 3147 & 122 & 66.5 & 0.241 & 0.233 & 4.83 & 925 & 12.2 \\
\hline A. L. & 3414 & 142 & 77.4 & 0.207 & 0.199 & 4.83 & 1004 & 14.3 \\
\hline
\end{tabular}

* Per cent of APO-LDL pool in intravascular compartment.

$\ddagger$ Calculated from serum decay curve by the method of Matthews (16); see text.

\& Calculated from U/P ratios; see text. 


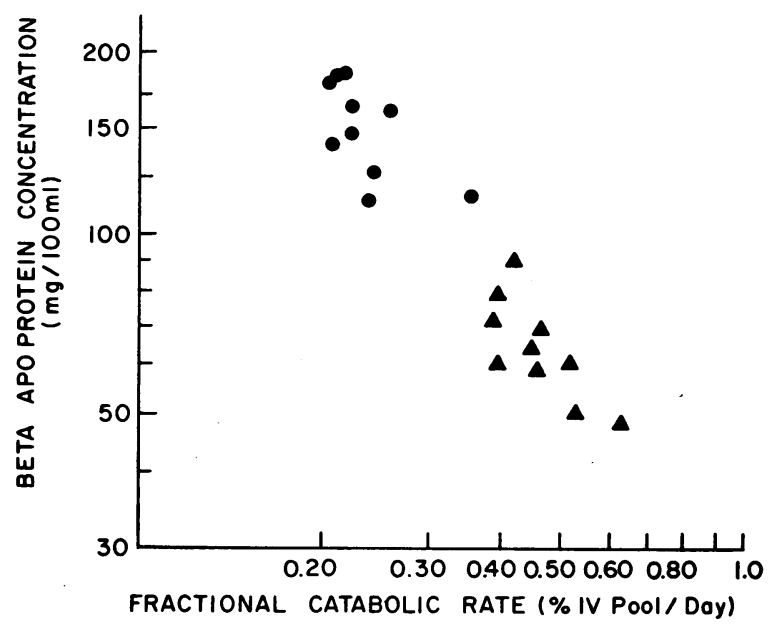

FIGURE 5 Relationships between beta apoprotein concentration $(\mathrm{mg} / 100 \mathrm{ml})$ and LDL fractional catabolic rate $(\%$ intravascular [IV] pool/day) in normal individuals $(\triangle)$ and patients with type II hyperlipoproteinemia $(\bullet)$.

the differences in the catabolism of LDL in normal individuals and patients with type II hyperlipoproteinemia resulted from inherent differences in the circulating LDL molecules, the turnover of ${ }^{125} \mathrm{I}-\mathrm{LDL}$ which had been isolated from a normal individual was studied in three subjects with type II disease who had previously received autologous ${ }^{125} \mathrm{I}-\mathrm{LDL}$. No differences in metabolic behavior were noted between the autologous and isologous proteins. The FCR, biological half-life, and $\mathrm{U} / \mathrm{P}$ ratios were virtually identical in each paired study.

\section{DISCUSSION}

In the present investigation, radioiodinated, purified low density lipoprotein $(\mathrm{d}=1.019-1.063 \mathrm{~g} / \mathrm{ml})$ was used to determine the behavior of LDL in normal individuals and patients with heterozygous familial type II hyperlipoproteinemia.

Studies of ${ }^{125} I-L D L$ turnover in normal individuals. The metabolic parameters of LDL apoprotein in normal individuals obtained with iodinated preparations used in these studies are comparable to the values reported by Volwiler et al. (19) using biosynthetically labeled ${ }^{35} \mathrm{~S}-\mathrm{LDL}$ and by Gitlin et al. (20), Walton et al. $(21,22)$, Scott and Winterbourn (23), and Hurly and Scott (24), using radioiodinated LDL. We did not observe a difference in LDL metabolism between men and women as reported by others $(23,24)$.

LDL has several singular metabolic features when compared with other plasma proteins. To begin with, although LDL is similar to other large serum proteins such as IgM and fibrinogen with regard to its distribution among the body compartments, the fractional catabolic rate of LDL is significantly greater than these proteins $(25,26)$. This suggests that LDL may be acted upon by a unique catabolic mechanism not shared by other proteins, or more likely, that LDL is subject to a specific degradation mechanism which acts in addition to a more generalized catabolic mechanism. This hypothesis is supported by studies which indicate that LDL clearance and degradation are linked to bile acid and cholesterol metabolism and transport. In this regard, we have shown that the administration of cholestyramine results in an increase in the fractional catabolic rate of LDL of type II patients (27). Since the action of cholestyramine is limited to the intraluminal binding of bile salts in the gastrointestinal tract, the effect of this perturbation on LDL metabolism would be mediated through changes in bile acid and/or cholesterol metabolism presumably occurring in the liver.

Another unusual attribute of LDL metabolism is the observation that, to a greater extent than other plasma proteins, the physiologic control of LDL concentration appears to be mediated via changes in catabolic rates rather than by alterations in synthetic rates (28). Thus, the normal patient with the lowest LDL concentration had the highest fractional catabolic rate and, in general, the plasma LDL concentration was inversely proportional to the fractional catabolic rate (Fig. 5). In contrast, the synthetic rate was not correlated with plasma LDL levels and was relatively constant. These observations are consonant with the finding that changes in dietary cholesterol and saturated fatty acid content exert their effect on LDL concentration in normal patients by changing the fractional catabolic rate of LDL whereas synthetic rates remain unchanged (27). A similar relationship between LDL concentration and fractional catabolic rate is observed in patients with type II hyperlipoproteinemia, but in this case the entire range of LDL concentrations is shifted to a higher level (Fig. 5).

Studies of ${ }^{125} I-L D L$ metabolism in patients with type II hyperlipoproteinemia. Patients with type II hyperlipoproteinemia had normal synthetic rates for LDL and a normal distribution of the lipoprotein in the body compartments. However, all patients demonstrated a striking decrease in the fractional catabolic rate of LDL which in each case was sufficient to account for the elevation in plasma LDL concentration. Since we could detect no differences in the metabolic behavior of autologous and isologous LDL from normal individuals when injected into patients with type II disease or into dogs, it is apparent that this defect in LDL metabolism is not intrinsic to the LDL molecule itself but instead resides in the catabolic mechanisms for LDL in these hyperlipoproteinemic patients. The abnormality in LDL catabolism in type II patients can therefore be visualized as a resetting of the LDL cata- 
bolic mechanism so that it operates at a lower range of fractional catabolic rates at the expense of an expanded plasma LDL pool.

Our results differ from previous studies of the behavior of LDL in hyperlipoproteinemic individuals. Walton et al. (21) and Scott and Hurley (29) found that the biological half-life and the fractional catabolic rate of LDL in type II patients were not significantly different from normal and concluded that excessive LDL synthesis was responsible for the hyperlipoproteinemia. It is likely from the data presented by these authors that many of these individuals did not have type II hyperlipoproteinemia. Furthermore it is possible that some of their patients represent an isolate within the broad definition of familial type II hyperlipoproteinemia who synthesize excessive amounts of LDL and who differ from our type II patients who display defective catabolism of LDL.

The finding of a decreased fractional catabolic rate in patients with type II hyperlipoproteinemia was unexpected since pathologic elevations in plasma protein concentration are usually due primarily to changes in the rate of protein synthesis. We therefore considered the possibility that the observed depression of FCR was a secondary metabolic phenomenon resulting from a primary change in synthetic rate or in the pool size of LDL. This hypothesis is made unlikely by the following considerations. In the first place, one cannot postulate that increased LDL synthesis led to an expanded LDL pool since the measured synthetic rates in hyperlipoproteinemic individuals are normal. In addition, it would be more reasonable to expect that the expansion of the LDL pool would be followed by a homeostatic increase in fractional catabolic rate so as to reestablish the original plasma protein concentration; this response is typical of the metabolic behavior of plasma IgG and to a lesser extent albumin when the pool sizes of these proteins are altered (30). In the second place, recent observations suggest that the fractional catabolic rate of LDL is independent of pool size. Studies from our laboratory have demonstrated that the reduction of LDL synthesis and decrease in the plasma pool of LDL in normal and hyperlipoproteinemic subjects induced by nicotinic acid are not accompanied by changes in the fractional catabolic rate (31). In addition, the fractional catabolic rate of LDL was normal in three individuals with familial hypobetalipoproteinemia who had synthetic rates and concentrations of LDL which were less than one-third of normal (32). Finally, Lees, and Ahrens (33) have demonstrated that the rate of disappearance of infused LDL was constant in an individual with abetalipoproteinemia, despite a constantly changing LDL pool size as LDL was removed from the plasma. For these various reasons, the observed decreased fractional catabolic rate in type II patients is not likely to be secondary to a primary change in LDL synthetic rate or pool size.

The metabolic defect in type II hyperlipoproteinemia. We have concluded that a decreased fractional catabolic rate of LDL is responsible for the hyperlipoproteinemia in patients with type II disease but the mechanism underlying this metabolic abnormality remains unclear. The metabolic defect responsible for the abnormal catabolism of LDL in type II hyperlipoproteinemia could be related to a primary disturbance in the metabolism of the intact lipoprotein or the LDL apoprotein, or it could be the consequence of a more fundamental abnormality in the metabolism of one of the lipid moieties of LDL.

As to the latter possibility, efforts to find a primary lipid abnormality have focused on the supposition that cholesterol synthesis was increased in type II hyperlipoproteinemia. In this regard, no consistent abnormality in the synthesis of cholesterol has been found in individuals with type II disease studied either by the incorporation of acetate $-{ }^{14} \mathrm{C}$ into cholesterol, by the analysis of cholesterol- ${ }^{14} \mathrm{C}$ decay curves and by fecal sterol balance techniques (34-38). Indeed, recent studies by Goodman and Noble (37) have shown that both normal and hypercholesterolemic individuals synthesize and degrade equal amounts of cholesterol daily.

Whereas cholesterol synthetic rates may be normal, the fractional rate of cholesterol degradation may be depressed in type II patients. Nestel, Whyte, and Goodman (39), using the two-pool model for cholesterol metabolism of Goodman and Noble, have shown that the plasma cholesterol concentration was not related to the production rate or the amount of cholesterol in the two exchangeable pools in normal and hyperlipidemic individuals. However, they determined that the clearance of plasma cholesterol, expressed as a fraction of the total mass of cholesterol in the plasma, is depressed in hypercholesterolemic patients. This observation on cholesterol metabolism appears to parallel our own regarding LDL metabolism and could be the more fundamental abnormality. Thus, it may be argued that a defect in the transport and/or degradation of cholesterol (either cholesterol bound to circulating LDL or cholesterol in some other body compartment) is responsible for the decreased catabolism of plasma LDL in type II patients. Just as reasonably, however, a defect in plasma LDL catabolism may be primary to a similar defect in cholesterol metabolism. In point of fact, the available data do not allow any conclusion as to which phenomenon is cause and which is effect. In any case, our questions concerning the abnormality in type II hyperbetalipoproteinemia have been focused 
and we now ask: what is the basis of the defect in LDL catabolism in this disease?

\section{REFERENCES}

1. Langer, T., W. Strober, and R. I. Levy. 1969. Familial type II hyperlipoproteinemia: a defect of beta lipoprotein apoprotein catabolism? J. Clin. Invest. 48: 49a. (Abstr.)

2. Fredrickson, D. S., and R. I. Levy. 1972. Familial hyperlipoproteinemia. In The Metabolic Basis of Inherited Disease. J. B. Stanberry, J. B. Wyngaarden, and D. S. Fredrickson, editors. McGraw-Hill Book Company, Inc., New York. 3rd edition. 545.

3. Fredrickson, D. S., R. I. Levy, and R. S. Lees. 1967. Fat transport in lipoproteins-an integrated approach to mechanisms and disorders. N. Engl. J. Med. 276: 32, $94,148,215$, and 273.

4. Levy, R. I., R. S. Lees, and D. S. Fredrickson. 1966. The nature of pre-beta (very low density) lipoproteins. J. Clin. Invest. 45:63.

5. McFarlane, A. S. 1958. Efficient trace-labelling of proteins with iodine. Nature (London). 182: 53 .

6. Adams, G. H., and V. N. Schumaker. 1968. Rapid molecular weight estimates for low-density lipoproteins. Anal. Biochem. 29: 117.

7. Lindgren, F. T., L. C. Jensen, R. D. Wills, and N. K. Freeman. 1969. Flotation rates, molecular weights and hydrated densities of the low-density lipoproteins. Lipids. 4: 337.

8. Bragdon, J. H.. R. J. Havel, and E. Boyle. 1956. Human serum lipoproteins. I. Chemical composition of four fractions. J. Lab. Clin. Med. 48: 36.

9. Sperry, W. M., and F. C. Brand. 1955. The determination of total lipides in blood serum. J. Biol. Chem. 213: 69 .

10. Kwiterovich, F. O., Jr., H. R. Sloan, and D. S. Fredrickson. 1970. Glycolipids and other lipid constituents of normal human liver. J. Lipid Res. 11: 322.

11. Lees, R. S., and F. T. Hatch. 1963. Sharper separation of lipoprotein species by paper electrophoresis in albumin-containing buffer. J. Lab. Clin. Med. 61: 518.

12. Lowry, D. H., N. J. Rosebrough, A. C. Fall, and R. J. Randall. 1951. Protein measurements with Folin phenol reagent. J. Biol. Chem. 193: 265.

13. Total cholesterol procedure N-24b. 1964. In Auto-Analyzer Manual. Technicon Co., Inc., Tarrytown, N. Y.

14. Kessler, G., and H. Lederer. 1965. Fluorometric measurement of triglycerides. In Automation in Analytical Chemistry. L. T. Skeggs, Jr., editor. Mediad, New York. 341 .

15. Bartlett, G. R. 1959. Phosphorus assay in column chromatography. J. Biol. Chem. 234: 466.

16. Matthews, C. M. E. 1957. The theory of tracer experiments with ${ }^{181}$ I-labelled plasma proteins. Phys. Med Biol. 2 : 36.

17. Nosslin, B. 1964. In Metabolism of Human Gamma Globulin ( $\left.\gamma_{\mathrm{ss}}-\mathrm{globulin}\right)$. S. B. Anderson, editor. Scientific Publications, Ltd., Oxford.

18. Berson, S. A., and R. S. Yalow. 1957. Distribution and metabolism of $\mathrm{I}^{181}$-labeled proteins in man. Fed. Proc. $16: 13 \mathrm{~s}$.

19. Volwiler, W., P. D. Goldsworthy, M. P. MacMartin, P. A. Wood, I. R. MacKay, and G. Fremont-Smith. 1955. Biosynthetic determination with radioactive sulfur of turn-over rates of various plasma proteins in normal and cirrhotic man. J. Clin. Invest. 34: 1126.
20. Gitlin, D., D. G. Cornwell, D. Nikasato, J. L. Oncley, W. L. Hughes, Jr., and C. A. Janeway. 1958. Studies on metabolism of plasma proteins in nephrotic syndrome. II. Lipoproteins. J. Clin. Invest. 37: 172.

21. Walton, V. W., P. J. Scott, J. Verrier Jones, R. F. Fletcher, and T. Whitehead. 1963. Studies on low density lipoprotein turnover in relation to atromid therapy. J. Atheroscler. Res. 3 : 396.

22. Walton, K. W., P. J. Scott, P. W. Dykes, and J. W. L. Davies. 1965. Alterations of metabolism and turnover of $\mathrm{I}^{181}$ low density lipoprotein in myxoedema and thyrotoxicosis. Clin. Sci. (London). 29: 217.

23. Scott, P. J., and C. C. Winterbourn. 1967. Low-density lipoprotein accumulation in actively growing xanthomas. J. Atheroscler. Res. $7: 267$.

24. Hurley, P. J., and P. J. Scott. 1970. Plasma turnover of $\mathrm{S}_{\boldsymbol{f}}$ 0-9 low-density lipoprotein in normal men and women. J. Atheroscler. Res. 11: 51 .

25. McFarlane, A. S., D. Todd, and S. Cromwell. 1964. Fibrinogen catabolism in humans. Clin. Sci. (London). 26: 415 .

26. Barth, W. F., R. D. Wochner, T. A. Waldmann, and J. L. Fahey. 1964. Metabolism of human gamma macroglobulins. J. Clin. Invest. 43: 1036.

27. Langer, T., R. I. Levy, and D. S. Fredrickson. 1969. Dietary and pharmacologic perturbation of beta lipoprotein $(\beta \mathrm{LP})$ turnover. Circulation. 40:(Suppl. III) 14.

28. Waldmann, T. A., and W. Strober. 1969. Metabolism of immunoglobulins. Prog. Allergy. 13: 1 .

29. Scott, P. J., and P. J. Hurley. 1969. Effect of clofibrate on low-density lipoprotein turnover in essential hypercholesterolaemia. J. Atheroscler. Res. 9: 25.

30. Freeman, T. 1965. Gamma globulin metabolism in normal humans and in patients. Ser. Haematol. 4: 76.

31. Langer, T., and R. I. Levy. 1970. Effect of nicotinic acid on beta lipoprotein metabolism. Clin. Res. 18: 458

32. Levy, R. I., T. Langer, A. M. Gotto, and D. S. Fredrickson. 1970. Familial hypobetalipoproteinemia: a defect in lipoprotein synthesis. Clin. Res. 18: 539.

33. Lees, R. S., and E. H. Ahrens, Jr. 1969. Fat transport in abetalipoproteinemia: the effects of repeated infusions of beta-lipoprotein-rich plasma. N. Engl. J. Med. 280: 1261.

34. Hellman, L., R. S. Rosenfeld, M. L. Eidinoff, D. K. Fukushima. T. F. Gallagher, C-I. Wang, and D. Adlersberg. 1955. Isotopic studies of plasma cholesterol of endogenous and exogenous origins. J. Clin. Invest. 34: 48.

35. Gee, D. J., J. Goldstein, C. H. Gray, and J. F. Fowler. 1959. Biosynthesis of cholesterol in familial hypercholesterolaemic xanthomatosis. Brit. Med. J. 2: 341.

36. Lewis, B., and N. B. Myant. 1967. Studies in the metabolism of cholesterol in subjects with normal plasma cholesterol levels and in patients with essential hypercholesterolaemia. Clin. Sci. (London). 32: 201.

37. Goodman, D. S., and R. P. Noble. 1968. Turnover of plasma cholesterol in man. J. Clin. Invest. $47: 231$.

38. Grundy, S. M., and E. H. Ahrens, Jr. 1969. Measurements of cholesterol turnover, synthesis and absorption in man carried out by isotope kinetic and sterol balance methods. J. Lipid Res. 10: 91.

39. Nestel, P. J., P. M. Whyte, and D. S. Goodman. 1969. Distribution and turnover of cholesterol in humans. $J$. Clin. Invest. 48: 982. 